\title{
A sociologia clandestina de Antonio Candido*
}

\author{
Rodrigo Martins Ramassote
}

Aclamado como um dos principais expoentes da crítica literária brasileira contemporânea, Antonio Candido tornou-se ao longo dos anos referência indispensável no exercício da disciplina que o consagrou. Em particular, no meio acadêmico paulista, sua obra converteu-se em fonte de inspiração e debate para inúmeras pesquisas relacionadas com a literatura brasileira. Ao mesmo tempo, nos últimos anos vem se ampliando consideravelmente a fortuna crítica voltada para o exame de seu legado intelectual, objeto de apropriação e disputa no interior do campo das letras.

No conjunto dessa vasta bibliografia ${ }^{1}$, predomina o esforço em deslindar as diretrizes teórico-metodológicas do projeto crítico de Candido, discutindo, de um lado, os principais achados e juízos analíticos de sua reflexão, e, de outro, a fecundidade de suas propostas no quadro mais geral das vertentes modernas de análise literária de cunho sociológico. Mais recentemente, alguns trabalhos abordaram a intrincada relação entre as áreas das ciências sociais e dos estudos literários nas principais obras do autor, salientando proximidades e aspectos comunicantes entre elas ${ }^{2}$.

É surpreendente constatar a pouca atenção dispensada ao último enfoque ao considerar-se sua importância para a compreensão do método crítico de Candido. Em geral, a discussão fica restrita à mera enunciação do lugarcomum "crítico sociológico", sem que se aprofundem questôes decisivas que merecem destaque: quais as matrizes ou as formulaçóes sociológicas
*Este artigo baseia-se no quarto capítulo de minha dissertação Ramassote, 2006. Agradeço a leitura atenta de Caio Roberto Bourg de Mello e o estímulo e sugestōes preciosas de Heloisa Pontes.

1.Para um amplo e exaustivo levantamento da bibliografia sobre Antonio Candido encontrada em trabalhos acadêmicos, livros e artigos, ver Dantas (2002).

2. Estou me referindo sobretudo aos estudos de Peirano (1991), Arantes (1992a, 1992b) e Jackson (2002).

3. Apesar de bastante 
comentada, muitas vezes com sentido depreciativo, a questão não recebeu uma avaliação cuidadosa. Alguns exemplos, coligidos de modo aleatório: Süssekind observa, com relação aos rumos tomados pela crítica literária brasileira na década de 1970, a importância "da vertente de crítica sociológica desenvolvida sobretudo em São Paulo, em torno da USPedeA. Candido" (2004,p. 54); Santiago assinala que a modalidade de crítica levada a cabo no campo dasletras paulista estaria marcada "por uma preocupação maior com os aspectos sociológicos da abordagem do texto brasileiro" (1982, p. 195); e Perrone-Moisés diz que Candido "é um crítico deformação einspiração sociológicas" (2000, p. $330)$.

4. Expressão utilizada pelo próprio autor para caracterizar o perfil acadêmico da sociologia produzida na capital paulista até meados do século XX (cf. Candido, 1957).

5. A escassez de estudos sobre essa dimensão crucial pode ser creditada a três fatores: a) declaraçôes de Candido subjacentes às análises literárias realizadas por Candido? Com quais vertentes das ciências sociais ele dialoga em seus ensaios? A partir do exame de "Dialética da malandragem" e "De Cortiço a cortiço", este artigo pretende destacar os modelos sociológicos que lastreiam seus referentes contextuais infusos, relacionando-os, respectivamente, com a própria obra de Candido na área das ciências sociais e as preocupaçôes temáticas desenvolvidas pela chamada "Escola paulista de sociologia".

Decerto vinculada à sua formação acadêmica e sua trajetória universitária iniciais, mas também ligada às suas principais convicções a respeito da literatura brasileira, essa "auspiciosa compenetração" entre a tradição do pensamento social brasileiro e a crítica literária constitui uma das dimensões mais peculiares da produção crítica de Candido, responsável, em parte, por sua ampla repercussão e destaque no meio intelectual contemporâneo 5 .

\section{Malandragem e família extensa}

Em 1970, Antonio Candido publica na Revista do Instituto Estudos Brasileiros o célebre ensaio "Dialética da malandragem", uma apreciação inovadora do romance Memórias de um sargento de milícias (1855), de Manuel Antonio de Almeida. Preparada durante quase uma década (cf. Vara, 1999), a publicação representou o amadurecimento de um esforço analítico perseguido ao longo da carreira profissional do crítico - "depois de muitos tateios e tendo já quarenta anos" -, ao estabelecer de modo sistemático as principais diretrizes de uma abordagem preocupada em "levar em conta a dimensão da sociedade sem fazer crítica sociológica, mostrando efetivamente (não apenas postulando teoricamente) a sublimação dos dados sociais e psicológicos em estrutura estética” (Jackson, 2002, p. 129).

Reavaliando, de saída, as consagradas interpretaçóes precedentes de $\mathrm{Me}$ mórias de um sargento de milícias - analisado, entre outros, por José Veríssimo, Mário de Andrade e Josué Montello -, a respeito da linhagem picaresca a que se alinharia o romance, Candido pondera que um "cotejo objetivo" das principais características de Leonardo Pataca, protagonista do romance, com as "do típico herói ou anti-herói picaresco, minuciosamente levantadas por [Frank] Chandler na sua obra sobre o assunto", revela, a rigor, diferenças substantivas tanto no tocante à origem e experiência social vivenciada pelo personagem, como em relação ao foco narrativo do romance. Com isso, em lugar do pícaro, Pataca encarnaria "o primeiro grande malandro que entra na novelística brasileira, vindo de uma tradição quase folclórica e corres- 
pondendo, mais do que se costuma dizer, a certa atmosfera cômica e popularesca de seu tempo, no Brasil. Malandro que seria levado à categoria de símbolo por Mário de Andrade em Macunaíma e que Manuel Antonio com certeza plasmou espontaneamente [...]" (Candido, 1993b, p. 27).

Desfeito o equívoco, Candido passa a considerar a modalidade peculiar de realismo que informa o romance, notando que o universo ficcional retratado pelo escritor carioca não deve ser considerado uma "reprodução fiel da sociedade em que a ação se desenvolve", seja em razão dos restritos limites topográficos descritos, seja devido ao conjunto das camadas sociais delineadas na obra. De fato, o perímetro espacial retratado pelo romance abrange apenas o núcleo urbano central da cidade do Rio de Janeiro, a partir do qual nenhum "personagem deixa o seu âmbito e apenas uma ou duas vezes o autor nos leva ao subúrbio" (Idem, p. 31). No que tange às camadas sociais, constata o crítico que quase todos os personagens são oriundos dos estratos médios da sociedade joanina, compondo "um tipo de gente livre modesta, que hoje chamaríamos pequena burguesia". Vê-se, portanto, que foram suprimidas as descrições das camadas dirigentes - a alta cúpula administrativa e os profissionais liberais - e das camadas básicas, compostas em sua grande maioria por escravos. Em decorrência,

[...] é provável que a impressão de realidade comunicada pelo livro não venha essencialmente dos informes, aliás relativamente limitados, sobre a sociedade carioca do tempo do Rei Velho. Decorre de uma visão mais profunda, embora instintiva, da função, ou "destino", das pessoas nessa sociedade; tanto assim que o real adquire plena força quando é parte integrante do ato e componente das situações. Manuel Antonio, apesar de sua singeleza, tem uma coisa em comum com os grandes realistas: a capacidade de intuir, além dos fragmentos descritos, certos princípios constitutivos da sociedade -, elemento oculto que age como totalizador dos aspectos parciais (Idem, p. 35).

No entender de Candido, a "eficiência e durabilidade" do romance de Manuel Antonio de Almeida derivam do processo de redução estrutural ou formalização estética - que transfigura no plano da composição ficcional os contornos de circunstâncias de ordem social vigentes no país naquele período, "profundamente significativas como modos de existência" (Idem, p. 36). E assim chegamos ao ponto que nos interessa discutir: qual o referente histórico-social que articula a leitura do romance de Manuel Antonio de Almeida em "Dialética da malandragem"? No intuito de compreender que minimizam a relevância da coexistência dessas áreas disciplinares em seu trabalho. Para que se possa evidenciar os termos em que Candido coloca a questão, basta a seguinte afirmação: "Aliás, eu não me considero sociólogo. Assim como o professor de matemática não é necessariamente matemático, fui professor de sociologia, dei conta do recado, mas nunca me considerei sociólogo" (Jackson, 2002, p. 125). Ver também Pontes (2001); b) ausência de indicaçōes explícitas dos modelos teóricos e debates de fundo no corpo do texto. Nos ensaios de Candido prevalece como ideal de escrita, na sua expressão sobre a obra de Bastide, a urbanidade crítica, isto é, um formato expositivo que procura "disfarçar ao máximo a erudiçāao, dissolvendo na tonalidade ensaística o peso da informação e a abstração dos princípios teóricos" (Candido, 1997, p. 14); c) uma convicção arraigada da recepção crítica da obra do autor-crescente nos últimos trinta anos que pressupõe não haver distinçōes, ou ma- 
tizes, entre o projeto autoral de Candido e o do discípulo Schwarz, como se o primeiro tivesse também participado do célebre "Seminário Marx”. Conviria averiguar se há de fato na obra de Candido uma reflexão abrangente sobre o "desenvolvimento desigual e combinado do capitalismo" (Schwarz, 1979, p. 109).

6. Para a elaboração deste artigo, utilizei, quando necessário, uma versão mimeografada traduzida com fins didáticos para o curso-segundo consta na página de rosto-de "Sociologial", $2^{\circ}$ semestre de 1974, na Unicamp. Agradeço a Jackson pela cópia fornecida. $\mathrm{O}$ tradutor não foi identificado.

7.Embora considere a propensão dos portugueses para o intercurso sexual com "pessoas de cor" como resultado da "natureza sincrética da formação étnica do português", a exemplo das formulações de Freyre e Vianna, principais referências mobilizadas para o ensaio, Candido pondera que o preconceito racial contra a mulher negra perdurou de os contornos mais gerais do protótipo sociológico que orienta a leitura de Candido, lançarei mão de outro trabalho do autor, o estudo "The Brazilian family" (1951).

Originalmente publicado no volume Brazil: portrait of a half a continent (1951), organizado por Lynn Smith e Alexander Marchant, "The Brazilian family", conforme Jackson informa, "foi encomendado por Lynn Smith e Alexander Marchant a Fernando de Azevedo, que, impossibilitado, sugeriu o nome de Antonio Candido para o substituir" (2002, p. 46). O ensaio volta-se para o "estudo sociológico da família brasileira" mediante a análise histórica de sua estrutura interna, função social e transformação no decorrer dos séculos XVI a XIX. Partindo do pressuposto de que a família patriarcal colonial "foi a base sobre a qual se desenvolve a moderna família conjugal, cujos traços só podem ser entendidos se examinarmos sua origem" (Candido, 1951, p. 1), Candido acompanha o processo de colonização do país a partir do perfil societário dos colonos ibéricos, constituídos sobretudo por integrantes das "zonas rurais e das camadas média e baixa da sociedade" portuguesa, assinalando a consolidação, após um período inicial de promiscuidade sexual decorrente da escassez de mulheres brancas ${ }^{7}$, de um "tipo ideal de família brasileira". Tal tipo amparou-se em dois núcleos correlatos: uma unidade central, legalizada, composta pelo casal branco e seus filhos legítimos, e, ao seu redor, um núcleo irregular, formando um numeroso apêndice familiar constituído "de escravos, agregados, índios, negros ou mestiços, no qual estavam incluídos as concubinas do chefe e seus filhos ilegítimos" (Idem, p. 4).

Com efeito, Candido afirma que no decorrer do processo de colonização, "graças à mistura étnica, o regime escravocrata e a baixa densidade da população, o abastardamento tornou-se muito comum, criando uma situação de fato na qual o núcleo da família legal funcionava como eixo de sustento. Na periferia, graças à devassidão dos brancos e às sobrevivências da poligamia africana e indígena, ele deve ter sido a regra, e só lentamente foi modificado pelas transformações nas funções da família patriarcal" (Idem, p. 11). Da reconstituição desse amplo quadro histórico, Candido diagnostica que a unidade familiar "formada dessa maneira não estava limitada a pais, filhos, irmãos e irmãs: tendia a integrar grupos maiores que constituíam juntos o sistema social por excelência do Brasil patriarcal, o qual se baseava na solidariedade do parentesco" (Idem, p. 8).

Molécula social básica durante o período colonial, o núcleo familiar sustentava a organização econômica, política e social, predominando como 
elemento decisivo na acomodação da dinâmica societária do país ${ }^{8}$. Como anota o autor: "Em certa extensão pode-se dizer que ela constituiu a organização fundamental do período colonial", daí concluindo-se que durante essa etapa a nação estava dividida em duas partes: "a familiar e a não-familiar" (Idem, p. 4).

Antes, porém, de prosseguir no cotejo anunciado, é necessário recuperar um aspecto do debate realizado por Mariza Corrêa no contundente ensaio "Repensando a família patriarcal brasileira" (1994). Nele, a autora procura discernir, por meio de "cuidadosa análise 'interna' dos textos principais da literatura sobre família no Brasil”, os pressupostos ideológicos envolvidos na concepção do conceito de família patriarcal, com ênfase nos clássicos trabalhos de Gilberto Freyre e Antonio Candido. Em que pese as diferenças de ponto de vista entre ambos, ao privilegiar como referência analítica o modelo estabelecido pela família patriarcal, "os autores parecem compartilhar com muitos outros estudiosos a ilusão de que o estudo da forma de organização familiar do grupo dominante, ou de um grupo dominante numa determinada época ou lugar, possa substituir-se à história das formas de organização familiar da sociedade brasileira" (Corrêa, 1994, p. 19). Desse modo, o estudo de Candido teria se limitado ao retrato do modelo dominante, apesar da variedade - e mesmo predomínio - de certas formas familiares alternativas. Observa ainda a autora que, na medida em que confere importância exagerada ao núcleo familiar na organização da sociedade brasileira do período colonial, Candido acaba atenuando a influência do aparelho estatal na constituição da ordem social do período. Em conseqüência: "É como se a sociedade colonial brasileira pudesse ser equiparada a uma sociedade primitiva, sem Estado [...]" (Idem, p. 25).

De acordo com Corrêa, Candido estabelece uma clivagem radical entre o "núcleo familiar onde imperava o patriarca e uma massa anônima totalmente entregue ao reino da natureza, sem qualquer norma cultural a regê-la” (Idem, p. 24). Nessa perspectiva, os habitantes do Brasil colonial "que não viviam dentro ou em volta da casa-grande" estariam por sua vez diante da "inexistência de qualquer tipo de norma de comportamento [...]” (Idem, p. 25) $)^{9}$. Embora o interesse principal da autora seja questionar o modelo ideológico predominante na produção teórica sobre o tema, no intuito de "sugerir a existência de um panorama mais rico", vou me centrar na sugestão indicada por Corrêa a respeito da suposta ausência de instituiçôes e mecanismos administrativos estatais que assegurem a ordem social, com o propósito de confrontá-la com os princípios regentes en- "modo acentuado no Brasil durante e após o período colonial”. Entretanto, "esse preconceito era mais social que racial e funcionava para a defesa do núcleo familiar legal e arrogante" (Candido, 1974, p. 3). Além disso, embora o artigo "pretenda dar uma visão ampla do problema”, os exemplos e argumentos desenvolvidos ficam circunscritos à região de influência histórica paulista.

8. O desfecho do artigo descreve tanto as mudanças das relações internas como os efeitos das transformaçōes sociais no seio da família patriarcal, devidos ao advento articulado das "ações de processos sociais, culturais e econômicos como a urbanização, industrialização, proletarização, imigração e aculturação" (Candido, 1974, p. 15).

9. Em entrevista a Jackson, Candido admite que "Mariza Corrêa diz com razão que eu trato da sociedade brasileira como se não houvesse Estado, só família [...]. Mas o Estado era fortee eu exagero demais a importância da família. 
Chego a dizer que o Brasil pode ser dividido em família e não-família" (Jackson, 2002, p. 166). contrados na "dialética da ordem e desordem”. Retornemos, agora, ao nosso ponto de partida.

Destaquei anteriormente que segundo Candido o romance de Manuel Antonio de Almeida logra representar a sociedade brasileira da primeira metade do século XIX mediante a apreensão intuitiva de um princípio estruturador profundo que não está relacionado com elementos de ordem documentária, mas com o fato de "ser construído segundo o ritmo geral da sociedade, visto através de um de seus setores" (Candido, 1993b, p. 45). Referida tanto à economia interna da narrativa, como à dinâmica geral da sociedade brasileira da primeira metade do século XIX, a expressão "dialética da ordem e desordem" define um código de condutas ancorado na ausência de valores e normas de convívio inflexíveis, favorecendo a alternância e a equivalência entre ordem estabelecida e desordem transgressiva.

Assim, no hemisfério da ordem, "positivo", encontram-se os principais personagens da obra, e as relações pessoais nele articuladas são pautadas por padrões sancionados pelas normas jurídicas e universalidade das regras, encarnadas no romance "pelo grande representante delas, major Vidigal" (Idem, p. 37). O hemisfério da desordem, por seu turno, abrange os personagens que convivem em "oposição ou pelo menos em relação duvidosa" com os parâmetros normativos instituídos. Do ponto de vista da construção do enredo, tal aspecto é discernível por meio da neutralidade e da ausência de qualquer juízo moral com que o narrador exprime o intercâmbio em pauta.

Ora, tal alternância displicente e tolerante entre o terreno do lícito e do ilícito somente seria possível pela frouxidão de mecanismos estatais que deixavam, a um só tempo, de cumprir suas funções com rigor nessa faixa social, coibir as condutas transgressoras e punir os infratores. De acordo com essa perspectiva, a imagem do major flagrado em ceroulas condensaria não apenas o ziguezague entre os pólos da ordem e da desordem, mas sobretudo a fragilidade do poder público no país, incapaz de sobrepôr-se à autoridade que a organização familiar detinha. Assim, a respeito da precária atuação vigilante do major Vidigal, Candido afirma ser ela "manifestação de uma consciência exterior, única prevista no seu universo" (Idem, p. 41). E conclui: "Ordem dificilmente imposta e mantida, cercada de todos os lados por uma desordem vivaz, que antepunha vinte mancebias a cada casamento e mil uniões fortuitas a cada mancebia” (Idem, p. 44).

Embora o foco analítico do estudo "The Brazilian family" esteja voltado para a abordagem de estrato social diverso de "Dialética da malandragem", 
não me parece despropositado perceber nesse referencial sociológico a matriz que articula o conjunto de consideraçôes de ordem contextual do ensaio. Observamos há pouco que o núcleo periférico da família patriarcal, formado por uniōes irregulares e filhos ilegítimos, acabava por contribuir "na formação da grande massa dos degradados socialmente, os vagabundos e elementos desordeiros, que constituíram grandes porções de nossa população no século XIX” (Candido, 1974, p. 12). Da mesma forma que o núcleo central da família patriarcal era convulsionado por uma "profunda corrente de irregularidade na qual os desejos e sentimentos procuravam compensar os obstáculos aos quais estavam submetidos pelo sistema impessoal de casamento" (Candido, 1993b, p. 13), Candido infere, a respeito do casamento no romance entre Leonardo e Luisinha, que, dada "a estrutura daquela sociedade, se Luisinha pode vir a ser uma esposa fiel e caseira, o mais provável é que Leonardo siga a norma dos maridos e, descendo alegremente do hemisfério da ordem, refaça a descida pelos círculos da desordem, onde o espera aquela Vidinha ou outra equivalente, para juntos formarem um casal complementar, que se desfará em favor de novos arranjos, segundo o costume da família brasileira tradicional” (Idem, p. 41).

Raça, classe e cortiço

Conforme Vinicius Dantas informa (cf. Candido, 2002), a versão acabada do ensaio "De Cortiço a cortiço", publicada finalmente em 1993, resulta da junção de duas versôes parciais publicadas inicialmente em meados dos anos de $1970^{10}$. Para discutir os principais argumentos de natureza sociológica do estudo, comecemos reproduzindo, esquematicamente, o elemento responsável pela construção do argumento do ensaio: o pequeno ditado humorístico popular - transcrito pelo autor logo no início do texto -, corrente na cidade do Rio de Janeiro no final do século XIX, que apregoava o seguinte: "Para Português, Negro e Burro, três pês: pão para comer, pano para vestir, pau para trabalhar”. Segundo Candido, o teor discriminatório contido nesse dito popular proporcionaria uma via de acesso ao "universo das relaçôes humanas d'O cortiço" (Candido, 1993c, p. 129), centrado na descrição do cotidiano vivido por moradores pobres de um cortiço fluminense do final do século XIX, período de transição do sistema baseado na utilização do trabalho escravo para o trabalho assalariado.

Numa primeira aproximação, o enunciado do ditado popular ostenta uma concepção detratora e xenófoba a respeito do imigrante português e
10. As versões foram recentemente reproduzidas por Dantas numa "montagem em duascolunas", com o título de "Duas vezes 'A passagem do dois ao três" (cf. Candido, 2002). A primeira, intitulada "A passagem do dois ao três", foi publicada integralmente na Revista de História, da Universidade de São Paulo (n. 100, v. L, ano XXV, 1974). Nesse artigo, Candido toma como interlocutor privilegiado o livro Análise estruturalderomances brasileiros (1972), de Sant'Anna. A segunda versão é uma transcrição da palestra pronunciada no II Encontro Nacional de Professores de Literatura (Rio de Janeiro, 30/7-2/8/1975), intitulada originalmente " $\mathrm{Li}$ teratura - Sociologia: análise de $O$ cortiço de Aluísio Azevedo", publicada no Cadernos da PUC (Série Letras e Artes), n. 28, 1976. 
11. Em tempo, seria oportuno também confrontar as consideraçôes acerca do universo ideológico da elite brasileira no final do século XIX apresentadas pelo ensaio com a descrição, baseada numa "sociologia do conhecimento", de tal estrato social encontradiça no capítulo final da tese $O$ método crítico de Sílvio Romero (1988). Nele, Candido almeja delinear as transformaçōes na mentalidade da época ocorridas com o advento dos setores burgueses na direção econômica e política da nação. do negro, reduzindo brutalmente o valor humano de ambos ao comparálos ao universo da animalidade. No entanto, ao examiná-lo com maior atenção, Candido detecta a existência de uma conotação implícita em seu significado inicial: a presença de uma visão derrogativa do trabalho que transparece na "feroz equiparação do homem ao animal, entendendo-se (e aí está a chave) que não é o homem na integridade do seu ser, mas o homem = trabalhador" (Idem, p. 129). Diante disso, o "dito não envolve, portanto, uma confusão ontológica, mas sociológica, e visa ocultamente a definir uma relação de trabalho (ligada a certo tipo de acumulação de riqueza), na qual o homem pode ser confundido com o bicho e tratado de acordo com essa confusão" (Idem, p. 129).

Identificado o substrato ideológico do ditado, Candido direciona sua análise para a demonstração da correspondência estrutural entre o universo valorativo apresentado pelo ditado e o enfoque narrativo presente no romance do escritor maranhense Aluísio Azevedo. Peça estratégica para se compreender o conteúdo do perfil classista embutido na visão de mundo do narrador do romance, afinado com o universo axiológico da elite brasileira finissecular ${ }^{11}$, o ditado, segundo Candido, remonta à ilusão do brasileiro livre desse período que,

[...] favorecido pelo regime da escravidão, [acaba] encarando o trabalho como derrogação e forma de nivelar por baixo, quase até a esfera da animalidade, como está no dito. O português se nivelaria ao escravo porque, de tamanco e camisa de meia, parecia depositar-se (para usar uma imagem usual do tempo) na borra da sociedade, pois trabalhava como um burro. Mas enquanto o negro escravo era de fato confinado sem remédio às camadas inferiores, o português, falsamente assimilado a ele pela prosápia leviana dos "filhos da terra", podia eventualmente acumular dinheiro, subir e mandar no país meio colonial (Idem, p. 130).

A partir da investigação da correspondência estrutural entre o ponto de vista do emissor virtual do ditado e a perspectiva do narrador do romance, Candido caracteriza uma série de relações pressupostas na atitude mental e na conduta do suposto emissor, sobretudo no que concerne ao relacionamento social e ao ajustamento inter-racial com os demais integrantes da estrutura socioeconômica do país, as quais se encontram transfiguradas no interior do "universo das relações humanas" do romance. E é exatamente no tratamento conferido a essa dimensão que Candido, a meu ver, acaba aproximando-se de uma fonte de inspiração importante para a execução de sua 
argumentação: as pesquisas sobre as relações raciais realizadas pela Escola paulista de sociologia.

Para abordar essa questão, gostaria de recuperar algumas formulações contidas no estudo Relaçôes raciais entre negros e brancos em São Paulo (1955), elaborado em conjunto por Florestan Fernandes e Roger Bastide, marco inaugural das pesquisas uspianas a respeito das relações raciais no país. Patrocinada pela Unesco com apoio da revista Anhembi, os sociólogos, segundo informa Arruda, "responsabilizaram-se pela pesquisa em São Paulo, realizada entre 1949 e 1951, e o conjunto de trabalhos escritos a propósito da investigação acabaram por revelar a construção de uma perspectiva inovadora sobre o problema” (Arruda e Garcia, 2003, p. 98). Como se sabe, ao contrário das perspectivas analíticas precedentes sobre o assunto, marcadas pela orientação racialista ou culturalista, o trabalho coordenado por Florestan e Bastide encarou a temática racial pelo ângulo da desigualdade social, preocupando-se em examiná-la com base no processo mais amplo de modernização e formação da estrutura de classes sociais no país, tomando como caso privilegiado a cidade de São Paulo ${ }^{12}$.

No artigo inicial do volume, redigido por Florestan Fernandes e intitulado "Do escravo ao cidadão", encontramos a descrição de um amplo painel da evolução da estrutura econômica paulista no período compreendido entre os séculos XVI e XIX, destacando a contribuição da mão-de-obra cativa nos diversos ciclos econômicos produtivos desse itinerário histórico. Nessa reconstituição, ganha destaque o período de transição das relaçôes servis de trabalho para o sistema de trabalho assalariado, no qual se processa a substituição parcial do negro, excluído pela competição com os imigrantes europeus e apenas reabsorvido lentamente no âmbito das novas condições desse novo sistema. Num momento de amplas transformações, foi concedida aos escravos, segundo Fernandes, "uma liberdade teórica, sem qualquer garantia de segurança econômica ou assistência compulsória; aos senhores e ao estado não foi atribuída nenhuma obrigação com referência aos libertos, abandonados à própria sorte daí em diante" (Fernandes, 1955a, p. 47). Tal processo provocou no negro liberto o desajuste de sua posição anteriormente estabelecida no sistema econômico paulista, ficando ele confinado, no plano ocupacional, a atividades profissionais subalternas, aquelas "mais humildes e mal remuneradas" (Idem, p. 51).

No segundo artigo, "Cor e estrutura social em mudança", Fernandes examina as implicações do legado da escravidão na constituição da posição
12. Acompanhando boa parte do pensamento social brasileiro, a fortuna crítica relativa à questão racial poderia ser periodizada em três etapas sucessivas: a) a primeira, compreendida, grosso modo, entre o final do século XIX e as primeiras décadas do $\mathrm{XX}$, "vinculada aos estudos afro-brasileiros (Nina Rodrigues, Arthur Ramos, M. Herskovits, René Ribeiro, Édison Carneiro e R. Bastide), estaria voltada à investigação da dinâmica aculturativa, preocupada então em delimitar a influência das culturas africanas no processo de constituição de uma cultura brasileira” (Maio, 2000, p. 124); b) a segunda, cujo principal representante é Gilberto Freyre, reinante a partir da década de 1930 , ressalta o caráter integrador e positivo da miscigenação, "e os impactos resultantes eo lugar que tradicionalmente vem sendo atribuído à raça negra” (Idem, p. 124); c) a terceira, decorrente do ciclo de pesquisas da Unesco realizadas na década de 1950, ainda sob o impacto do holocausto, teria o propósi- 
to de promover um conjunto integrado de atividades intelectuais dispostas a "combater a ideologia racista que serviu de suporte para a montagem e operação da máquina infernal nazista” (Idem, p. 124). Entre 1951 e 1952, o Brasil é eleito área de investigação privilegiada para o exame das relações raciais em razão da convicção de que era um modelo de convivência harmoniosa e aceitação das diferenças raciais, com o objetivo "de oferecer ao mundo lições de civilização à brasileira em matéria de cooperação entre raças" (Idem, p. 116). Entre as regiōes selecionadas como locus empírico estavam Bahia (a cargo de Thales de Azevedo e Charles Wagley), Pernambuco (René Ribeiro), Rio de Janeiro (Luis Costa Pinto) e São Paulo (Florestan Fernandes e Roger Bastide). Sobre da vertente paulista, ver Schwarcz (1996; 1999). social e profissional do negro no período republicano. Segundo ele, tais implicações

[...] podem ser resumidas a três: $1^{\circ}$ ) na seleção da mão-de-obra, sempre prevaleceram motivos que nada têm a ver com a raça ou a cor dos trabalhadores; $2^{\circ}$ ) a raça ou a cor não exerceram por si mesmas, aparentemente, nenhuma influência como fatores sociais construtivos na constituição ou na transformação da ordem de ajustamento inter-racial; $3^{\circ}$ ) as condições sociais de exploração econômica da mão-deobra escrava favoreceram a formação de símbolos sociais e de padrões de comportamento polarizados em torno da raça ou da cor, os quais se ligaram, como causa ou como condição operante, à determinação da dinâmica dos ajustamentos entre negros e brancos em São Paulo (Fernandes, 1955b, p. 67).

Para Fernandes, o perfil da estratificação social em São Paulo é antes o resultado da posição que "cada uma das raças em contato ocupavam no sistema de relações materiais", que decorrência das diferenças raciais específicas. Nas palavras do autor: "À estratificação social em São Paulo corresponde ou se superpõe uma estratificação interétnica e racial" (Idem, p. 68). Como indica Peixoto, "a tese básica defendida nesse capítulo é que a discriminação racial não é praticada em função de 'ojerizas' associadas a diferenças raciais, mas fruto das desigualdades sociais, produzidas em contexto escravista. Assim, o preconceito e a discriminação são explicados como meios de preservação da ordem social escravocrata" (Peixoto, 2000, p. 188). Ou seja, o que define e possibilita o preconceito racial, segundo as sugestivas reflexões de Fernandes, é a posição subalterna ocupada pelo negro na estrutura social paulista. Nesse processo, "os atributos propriamente raciais contavam como decorrência. Por isso, para eles [brancos] as 'raças' negras se compunham de indivíduos que se caracterizavam duplamente: pela condição de escravo e pela cor da pele" (Fernandes, 1955b, p. 91). Predomina, assim, uma percepção que concebe as diferenças entre as condições da situação econômica e a posição social de negros e brancos como determinantes na deflagração de atitudes e comportamentos discriminatórios.

Nesse quadro societário, conforme Florestan Fernandes,

[...] a cor foi, portanto, selecionada como marca racial que serviria para identificar socialmente os negros e mestiços. Ela passou a ser um símbolo de posição social, um ponto de referência imediatamente visível e inelutável, através da qual se poderia presumir a situação de indivíduos isolados, como socius e como pessoa, tanto 
quanto definir o destino de uma "raça". Nesse sentido, pode-se afirmar que a cor não só transparecia na "anatomia" da sociedade escravocrata de São Paulo, mas ainda intervinha dinamicamente em sua "fisiologia". De um lado, ela permitia distinguir os indivíduos, por meio de caracteres exteriores, de acordo com sua posição na estrutura social. De outro, funcionava como um núcleo de condensação e de ativação de uma série de forças sociais, que mantinham a unidade e a estabilidade da ordem vigente (Idem, p. 70).

Em outras palavras, o ajustamento social entre senhores e escravos foi sustentado e redefinido pela cor da pele dos indivíduos, que se tornou "uma espécie de índice da condição social da pessoa", traço distintivo selecionado na identificação social dos ocupantes das camadas sociais que emergiam na capital paulista. Se a função social da discriminação racial na antiga sociedade escravista paulista consistia na perpetuação da ordem senhorial vigente ao operar a segregação rigorosa das castas - por meio das diferentes modalidades de discriminação apontadas no texto -, com a desagregação do regime de trabalho escravista e com a ascensão coletiva dos negros e mestiços ao estatuto jurídico-político de cidadãos, esse mesmo objetivo, contudo, conserva-se intacto, não havendo alteração significativa no antigo padrão de preconceito racial e "tratamento recíproco assimétrico" (Idem, p. 112).

Com essas considerações podemos retomar o ensaio "De Cortiço a cortiço", evidenciando o cerne da questão que me levou a essa longa digressão pelo trabalho de Florestan Fernandes: só se pode compreender devidamente a natureza da visão de mundo discriminadora e xenófoba compartilhada pelo emissor virtual do dito "Para português, negro e burro, três pês: pão para comer, pano para vestir e pau para trabalhar" e pelo foco narrativo que anima a estruturação de $O$ cortiço, de Aluísio Azevedo, quando levamos em consideração a influência da produção intelectual da Escola de sociologia paulista na caracterização elaborada por Candido a respeito da dinâmica social interativa entre os envolvidos pelo ditado. Num trecho posterior do ensaio, ele é retomado por Candido para "insistir no seu baixo caráter de formulação ideológica” (Candido, 1993c, p. 132) e descrever com maior minúcia o emissor latente do mote trocista, isto é, o brasileiro abastado do final do século XIX. Observemos mais atentamente essa descrição, pois são notáveis as sintonias de padróes de comportamento dos representantes da camada senhorial da elite paulista descritos por Candido e por Florestan Fernandes. Eis a passagem: 
O tipo de gente que o [dito] enunciava sentia-se confirmada por ele na sua própria superioridade. Essa gente era cônscia de ser branca, brasileira, livre, três categorias bem relativas, que por isso mesmo precisavam ser afirmadas com ênfase, para abafar dúvidas num país onde as posições eram tão recentes quanto a própria nacionalidade, onde a brancura era o que ainda é (uma convenção escorada na cooptação dos "homens bons"), onde a liberdade era uma forma disfarçada de dependência. Daí a grosseria agressiva da formulação, feita para não deixar dúvidas: eu, brasileiro nato, livre, branco, não posso me confundir com o homem de trabalho bruto, que é escravo e de outra cor [...] (Idem, p. 132).

Ainda que assimilados de modo particular, pode-se detectar uma estreita relação das considerações de Candido com os resultados obtidos pela pesquisa coordenada por Florestan Fernandes e Roger Bastide. É o caso, por exemplo, do empenho das elites ilustradas na manutenção de suas prerrogativas de classe, potencialmente em risco nesse momento, recorrendo ao preconceito de cor e à discriminação social como componentes decisivos na manutenção da desigualdade social entre as camadas constitutivas da estrutura social de São Paulo. O trecho a seguir, extraído de uma das versões preliminares já mencionadas da versão final do ensaio de Candido, torna essa suposta fonte de inspiração mais evidente:

Vemos, então, que uma leitura orientada pelos traços culturais e sociais incorporados à estrutura literária mostra que, neste romance, o Branco é por excelência, não o que tem cor branca, mas o que pertence ou vai pertencer à camada dominante. Sobretudo o Português. E ainda: que o Negro não é o de cor preta, mas todos os que pertencem às camadas sociais cujos membros são, no limite, tratados como escravos, isto é, aqueles sobre os quais recai o trabalho produtivo. É a massa brasileira do Cortiço, feita de brancos, negros, mulatos, caboclos, cafusos. Os portugueses que, em vez de tenderem à classe dominante, tendem à classe dominada, se equiparam essencialmente ao Negro, como Jerônimo. Portanto, Negro = Trabalhador. A classificação étnica inicial se refaz, é redefinida segundo critérios sociais e econômicos (Candido, 2002, p. 66; grifos nossos).

É pouco provável que Candido não tenha tomado conhecimento dos principais diagnósticos e resultados alcançados pelo conjunto de pesquisas realizadas pela chamada Escola Paulista de Sociologia acerca das relaçóes raciais no país, uma vez que nesse período ele continuava vinculado ao corpo docente da Faculdade de Filosofia, Ciências e Letras de São Paulo 
como professor de sociologia, e, principalmente, considerando-se seu íntimo relacionamento afetivo e intelectual com o principal mentor e coordenador das pesquisas, o sociólogo Florestan Fernandes: "Fomos companheiros de trabalho, dia a dia, durante uns quinze anos; e temos uma intimidade sem reservas [...]", o que possibilitou, dessa forma, atestar o surgimento "da cadeia de preocupaçôes e raciocínios que levaram Florestan às suas posições pessoais" (Candido, 2001, p. 14) ${ }^{13}$.

Para arrematar esta discussão, vejamos rapidamente os comentários de Affonso Romano de Sant'Anna sobre o ensaio de Candido em pauta, os quais podem auxiliar na confirmação de nossas sugestôes. Em estudo publicado em 1977, "Curtição: O Cortiço do Mestre Candido e o meu", Sant'Anna retoma parte das questôes e objeções apontadas por Candido em "A passagem do dois ao três", preocupado "não digo em responder, mas em refazer alguns pontos do meu exercício analítico” (Sant’Anna, 1977, p. 214). Em sua avaliação,

[...] outro dado que mereceria ser mais problematizado entre os selecionados pelo professor Candido é o elemento racial, ou melhor, da cor das pessoas descritas. Assim o Mestre faz a seguinte afirmativa não de todo precisa em relação ao texto do romance: "Em termos de cor o grupo pobre é mais complexo, porque formado por brancos, mestiços e negros, enquanto no sobrado só há brancos. Ou, por outro lado, nem todos os brancos estão no sobrado, mas nele só há brancos” (Idem, p. 229; grifos nossos).

Nessa direção, Sant'Anna adverte que, ao contrário do que Candido afirma, podemos encontrar de fato três empregados domésticos negros alojados no sobrado: Valentim, Leonor e Isaura. Em decorrência, a inoperância do ditado humorístico selecionado por Candido, que não abarca todas as relações sociais possíveis descritas no interior do romance. Por fim, o autor conclui, a partir novamente de um trecho destacado do ensaio de Candido, que

[...] não há, é verdade, o elemento racial, o negro, que a frase coligida pelo Mestre tem, mas segundo se depreende de sua afirmação o negro é mais aspectual que estrutural, pois "Negro não é o da cor preta, mas todos os que pertencem às camadas sociais cujos membros são, no limite, tratados como escravos, isto é, aqueles sobre os quais recai o trabalho produtivo" (Idem, p. 231).
13. Esse aspecto pode ser corroborado, em larga medida, pela leitura do conjunto de depoimentos realizados por Candido sobre Florestan Fernandes, reunidos em Florestan Fernandes (2001). Ali ele reitera alguns dos principais achados explicativos resultantes desse ciclo de pesquisas, verificando a influência marcante dessa temática para o desenvolvimento da obra do sociólogo paulista. Além disso, em "A Faculdade no centenário da abolição" (1995), ao evidenciar a contribuição da Faculdade de Filosofia da USP para a transformação nos estudos sociais sobre a sociedade brasileira, Candido ressalta a importância da pesquisa sobre as relações raciais aí efetuada para o desvendamento dos mecanismos de opressão e manutenção das desigualdades sociais, obstáculos para a construção de uma democracia plena no país. 
14.Para uma apreciação alentada, num registro quase etnográfico, da trajetória acadêmica inicial, participação como membro integrante do grupo Clima e principais características do perfil analítico do projeto intelectual de Candido, ver Pontes (1998).

15. Para uma análise detalhada do arcabouço institucional da área depois, em 1991, departamento-de Teoria Literária e Literatura Comparada no período compreendido entre 1961 e 1978, com destaque para o regimento disciplinar, a estrutura curricular, as características do quadro docente, o conteúdo das disciplinas oferecidas, as áreas e as linhas temáticas de pesquisa e os mecanismos envolvidos na construção da identidade profissional de seus membros componentes, ver Ramassote (2006).

16. Com razão Jackson afirma que "sua opção posterior pela crítica literária não pode ser compreendida sem que se considerem as perspectivas teóricas adquiridas nas ciências sociais" (Jackson, 2006, p. 265).
O romance de Aluísio Azevedo descreve, de fato, a presença de três empregados domésticos negros abrigados no sobrado do comendador Miranda, constituindo uma rede de relações sociais interativas em diferentes níveis com seus proprietários. Contudo, devemos observar que, na medida em que os empregados negros se encontram inseridos num ambiente espacial marcado pela riqueza e pelo prestígio - na expressão empregada por Candido, um "lugar de rico" -, coabitando e gravitando diretamente a vida íntima dos membros principais da família do próspero comerciante de tecidos e comendador, a característica racial prévia deles é redefinida em função da posição e do status social adquirido pela permanência no interior do casarão. Ao afirmar que no bojo do sobrado encontram-se apenas brancos, Candido não desconhece a ordem de fatos apresentada pelo romance, mas, ao contrário, considera-a numa outra perspectiva, interessada na conexão dos privilégios de classe e desigualdades econômicas, preconceitos raciais e exclusão social.

Ao encerrar este artigo, gostaria de sugerir a possibilidade de apreender parte substantiva da produção crítica de Antonio Candido a partir do diálogo estreito e criativo com questóes de fundo relacionadas com o temário do pensamento social brasileiro. Ao contrário da opinião sustentada por Peirano, para quem a obra de Candido pode ser incluída "na linhagem do pensamento antropológico no Brasil como alguém que fez antropologia sem querer" (Peirano, 1991, p. 25), prefiro encará-la, em grande parte, como marcadamente sintonizada com o repertório de preocupações temáticas típicas das ciências sociais. Embora a ambigüidade profissional que enredara o início da trajetória intelectual e acadêmica de Candido ${ }^{14}$ - cindida entre a crítica literária e a pesquisa na área de sociologia - estivesse virtualmente dissipada nesse momento, quando já se encontrava firmada sua identidade profissional como principal mentor e responsável pela área de Teoria Literária e Literatura Comparada na FFCL-USP ${ }^{15}$, os ensaios abordados neste artigo remetem a uma dupla inserção de tradições disciplinares, a qual pode ser discernida nos conteúdos temáticos privilegiados por Candido, alinhados ao campo de investigações tradicionais da reflexão sociológica no Brasil ${ }^{16}$. A despeito da enfática preocupação com a análise dos desafios formais das obras literárias, Candido aborda os principais romances da literatura brasileira pela discussão de questôes de ordem sociológica, relati- 
vas, entre outras, à constituição da ordem pública, da abrangência dos laços familiares, da formação da estrutura de classes e consolidação do Estadonação. Preocupando-se em deslindar como "a realidade do mundo e do ser se torna, na narrativa ficcional, componente de uma estrutura literária, permitindo que esta seja estudada em si mesma, como algo autônomo" (Candido, 1993a, p. 9), o autor, em seus principais ensaios, realiza uma reflexão profunda sobre tal "realidade do mundo", baseada numa síntese particular que assimila e explora, de modo criativo, autores, tradições e esquemas analíticos sociológicos de diversas procedências na composição de um projeto autoral cujas principais coordenadas articulam ensaísmo social e crítica literária, ciências sociais e análise estética.

Dessa perspectiva, é possível entrever na base deles, quando apreendidos em sequiência, numa espécie de díptico, a existência de uma problemática comum de fundo, já esboçada nas páginas anteriores: a descrição da experiência social coletiva vivenciada por grupos marginalizados no interior do processo de formação social do país ${ }^{17}$. Na leitura de "Dialética da malandragem", cujo referente sociológico remonta ao Brasil joanino do início do século XIX, Candido assinala a dificuldade de consolidação da soberania interna e regulamentação das condutas pela ausência de mecanismos de coerção e controle de origem estatal atuantes no interior da camada formada por "gente livre e modesta". Essa existência precária favorecia o predomínio de "formas espontâneas de sociabilidade", nas quais a ordem familiar e as formas tolerantes de sociabilidade imperavam sobre os ditames reguladores do poder público, "numa vasta acomodação geral que dissolve os extremos", em que "uns poucos livres trabalhavam e os outros flauteavam ao Deus dará, colhendo as sobras do parasitismo, dos expedientes, das munificências, da sorte ou do roubo miúdo" (Candido, 1993b, p. 44).

Em "De Cortiço a cortiço", por sua vez, Candido examina a peculiaridade das relações e do preconceito racial no país. Embora esteja novamente abordando a trajetória de grupos sociais desfavorecidos, deparamonos com a influência de um contexto histórico-social diverso: as relações de solidariedade e auxílio mútuos, possíveis num estágio embrionário da progressiva consolidação do Estado nacional na primeira metade do século XIX, cedem espaço - numa etapa avançada do processo de acumulação capitalista, assalariamento, remodelação do espaço público e declínio do núcleo familiar - ao conflito acirrado de classes envolvendo grupos étnicos afro-brasileiros, mestiços, imigrantes desfavorecidos e brancos pobres oriundos da "massa amorfa de instáveis sociais" (Candido, 1988, p. 120) ${ }^{18}$.
17. Embora Jackson já tenha indicado a importância do conceito de formação em alguns dos principais trabalhos de Candido, evidenciando em particular como a Formação da literatura brasileira e Os parceiros do Rio Bonito empenham-se, cada um a seu modo, "em compreender o processo histórico e os fundamentos da nação brasileira, apesar de tratarem de dimensōes diferentes da realidade e da história" (Jackson, 2002, p. 74), considero que essa assertiva pode ser estendida aos ensaios ora analisados. Como procurei demonstrar, ambos abordam de modo privilegiado a realidade e a dinâmica social experimentada por grupos étnicos afro-brasileiros, imigrantes pobres e camadas dependentes perante o influxo da consolidação histórica do Estado nacional brasileiro.

18. Essa categoria social inquieta o autor desde o início de sua trajetória intelectual. Em $O$ método crítico de Sílvio Romero, no capítulo dedicado ao exame da obra do crítico sergipano em seu contexto social, há a seguinte referência ao tra- 
balho de Caio Prado Júnior, pioneiro e principal teórico do assunto debatido em especial no clássico Formação do Brasilcontemporâneo (1942): "A este respeito, é indispensável consultar o estudo que Caio Prado Júnior consagra ao problema, esclarecendo-o e interpretando-o de maneira profunda”, sobretudo o capítulo "Organização social”, "onde está a melhor análise e interpretação que conhecemos do problema" (Candido, 1988, p. 121). Não obstante a menção elogiosa, o tratamento de Candido a esse segmento social difere do tratamento do historiador marxista: enquanto este estava preocupado com o desenvolvimento e a superação do complexo socioeconômico do sistema colonial português para aimplantação plena do capitalismo no Brasil, A. Candido, a meu ver, preocupava-secomoimpacto desse avanço nos segmentos dominados. Essa "rotação de perspectiva” permite a Candido não incorrer nos mesmos deslizes e problemas que acometem a análise de Caio Prado no capítulo citado, no qual se podem encontrar consideraçōes
Em lugar da reversibilidade entre a "ordem e desordem", encontra-se o princípio estrutural da "dialética do espontâneo e dirigido" regendo o processo de remodelação do espaço físico interno do cortiço e, por extensão, o ritmo do avanço do capitalismo no país, deslocando com isso a resolução das tensões sociais para o âmbito da esfera estatal. Nessa fase, em que se destacam o "mundo do trabalho, do lucro, da competição, da exploração econômica visível”, os grupos minoritários, submetidos à exploração econômica e tolhidos pelo preconceito racial, enfrentam os reveses de um processo em que "brancos, negros e mulatos eram igualmente dominados e explorados por esse bicho-papão dos jacobinos, o português ganhador de dinheiro, que manobrava tanto cordéis de ascensão social e econômica nas cidades" (Candido, 1993c, p. 138) ${ }^{19}$.

Inspiração marxista, sociologia crítica, engajamento social e análise literária sensível se combinam, sem alarde, nos principais estudos críticos de Candido, coalescência que amplia seu interesse e sua abrangência, e contribuiu para que os artigos abordados granjeassem a ampla notoriedade e repercussão alcançadas no meio intelectual brasileiro.

\section{Referências Bibliográficas}

Arantes, Paulo Eduardo. (1992a), "Providências de um crítico literário na periferia do capitalismo". In: D’InCAO, Maria Ângela \& SCARABÔTOLO, Eloísa Faria (orgs.), Dentro do texto, dentro da vida: ensaios sobre Antonio Candido. São Paulo, Companhia das Letras.

- (1992b), Sentimento da dialética. Rio de Janeiro, Paz e Terra.

ArrudA, Maria Arminda do Nascimento. (1994), "A trajetória da pesquisa na sociologia”. Estudos Avançados, 8 (22), São Paulo.

(1996), “A imagem do negro na obra de Florestan Fernandes”. In: Schwarcz, Lilia K. Moritz \& QueIroz, Renato da Silva (orgs.). Raça e diversidade. São Paulo, Edusp/Estação Ciência.

. (1997), "Dilemas do Brasil moderno: a questão racial na obra de Florestan Fernandes". Idéias, 4 (1/2), jan./dez., Campinas.

. \& GARCIA, Sylvia Gemignani. (2003), Florestan Fernandes, mestre da sociologia moderna. Brasília, Paralelo 15.

CAndido, Antonio. (1951), “The Brazilian family”. In: SMith, T. Lynn \& Marchant, Alexander (orgs.). Brazil: portrait of half a continent. Nova York, The Dryden Press.

(1957), “A sociologia no Brasil”. Tempo Social, 18 (2), jun., São Paulo. 
(1974), "A família brasileira”. Apostila do curso Sociologia Io, 2o semestre.

Campinas, Unicamp.

. (1978), "Prefácio". In: Fernandes, Florestan. A condição de sociólogo. São Pau-

lo, Hucitec.

. (1988), O método crítico de Sílvio Romero. São Paulo, Edusp.

. (1993a), "Prefácio". In: . O discurso e a cidade. São Paulo, Duas Cidades.

. (1993b), "Dialética da malandragem". In: $O$ discurso e a cidade. São

Paulo, Duas Cidades.

. (1993c), "De Cortiço a cortiço". In: . O discurso e a cidade. São Paulo,

Duas Cidades.

. (1995), "A Faculdade no centenário da abolição". In: . Vários escritos.

São Paulo, Duas Cidades.

. (1997) "Prefácio". In: Bastide, Roger. Poetas do Brasil. São Paulo, Edusp/

Duas Cidades.

. (2000), Literatura e sociedade. São Paulo, PubliFolha.

. (2001), Florestan Fernandes. São Paulo, Fundação Perseu Abramo.

. (2002), "Duas vezes a passagem do dois ao três”. In: DANTAS, Vinicius (org.).

Textos de intervenção. São Paulo, Duas Cidades.

CORRÊA, Mariza. (1994), "Repensando a família patriarcal brasileira”. In: ArANTES,

Antonio Augusto et al. (orgs.), Colcha de retalhos. São Paulo, Editora da Unicamp.

Dantas, Vinicius. (2002), Bibliografia de Antonio Candido. São Paulo, Duas Cidades.

Fernandes, Florestan. (1955a), “Do escravo ao cidadão”. In: Fernandes, Florestan \&

BAStide, Roger (orgs.). Relaçôes raciais entre negros e brancos em São Paulo. São

Paulo, Anhembi.

. (1955b), "Cor e estrutura social em mudança”. In: Fernandes, Florestan \&

BASTide, Roger (orgs.), Relaçôes raciais entre negros e brancos em São Paulo. São

Paulo, Anhembi.

FukUi, Lia F. G. (1986), “Estudos e pesquisas sobre família no Brasil”. In: Cerqueira,

Eli Diniz (org.). BIB - O que se deve ler nas ciências sociais no Brasil, n. 1, São

Paulo, Cortez/Anpocs.

JACKSON, Luiz Carlos. (2002), A tradição esquecida. Belo Horizonte, Editora da UFMG. . (2006), “Sociologia como ponto de vista”. Tempo Social, 18 (1), jun., São Paulo.

Maio, Marcos Chor. (2000), "O Projeto Unesco: ciências sociais e o 'credo racial brasileiro”. Revista USP, 46, jun./ago., São Paulo.

Peirano, Mariza G. S. (1991), "O pluralismo de Antonio Candido”. In: Uma

antropologia no plural. Brasília, Editora da UnB.

Peiхото, Fernanda Arêas. (2000), Diálogos brasileiros: uma análise da obra de Roger

Bastide. São Paulo, Edusp. no mínimo questionáveis sobre a influência do legado sociocultural de origem ameríndia e africana no processo de formação do país, o que curiosamente não suscitou, salvo engano, nenhum comentário da recepção crítica da obra de Caio Prado Júnior.

19. A propósito da clivagem realizada pela USP e pela ELSP no padrão de estudos sociológicos brasileiros, Candido assinala que "a importância da Sociologia e Política e da Faculdade foi deslocar a sociologia brasileira das classes dominantes para as classes dominadas" (Jackson, 2002 , p. 15 ; grifos nossos). E ainda: "Na Faculdade de Filosofia, a partir de 1940, houve uma espécie de reviravolta empírica, fazendo com que fosse privilegiada a pesquisa; e as pesquisas se concentraram nessas classes subalternas, cessando praticamente o estudo sobre as privilegiadas. Assim, passamos a estudar o negro, o índio destribalizado, o trabalhador urbano, o lavrador pobre, o pescador etc." (Candido, 2001, p. 50). 
Perrone-Moisés, Leyla. (2000), “Antonio Candido: o amor à literatura”. In:

Inútil poesia. São Paulo, Companhia das Letras.

Pontes, Heloisa. (1998), Destinos mistos: os críticos do grupo Clima em São Paulo. São

Paulo, Companhia das Letras.

. (2001), "Entrevista com Antonio Candido". Revista Brasileira de Ciências Sociais,

16 (47), out., Bauru, SP, Edusc.

Ramassote, Rodrigo M. (2006), A formação dos desconfiados: Antonio Candido e a crítica literária acadêmica (1961-1978). Dissertação de mestrado. Instituto de Filosofia e Ciências Humanas da Unicamp, Campinas.

Sant'Anna, Affonso Romano de. (1977), "Curtição: o Cortiço do Mestre Candido e o meu”. In: _. Por um novo conceito de literatura brasileira. Rio de Janeiro, Eldorado.

Santiago, Silviano. (1982), Vale quanto pesa. Rio de Janeiro, Paz e Terra.

SchwarCZ, Lilia K. Moritz. (1996), "Questão racial no Brasil”. In: SCHWARCZ, Lilia

K. Moritz \& ReIs, Letícia Vidor de Sousa (orgs.). Negras imagens. São Paulo, Edusp.

. (1999), "Questão racial e etnicidade". In: Miceli, Sergio (org.), O que ler na ciência social brasileira (1970-1995). São Paulo, Idesp, vol. 1.

Schwarz, Roberto. (1979), "Entrevista com Gildo Marçal Brandão e O. C. Louzada

Filho”. Encontros com a Civilização Brasileira, n. 15, Rio de Janeiro, Civilização Brasileira.

. (1987), "Pressupostos, salvo engano, de 'Dialética da malandragem”". In:

Que horas são? São Paulo, Companhia das Letras.

. (1999), "Adequação nacional e originalidade crítica". In: . Seqüências brasileiras. São Paulo, Companhia das Letras.

Smith, T. Lynn \& Marchant, Alexander. (1951), Brazil: portrait of Half Continent. Nova York, The Dryden Press.

SüsseKIND, Flora. (2004), Literatura e vida literária. Belo Horizonte, Editora da UFMG. Vara, Teresa. (1999), "Esboço de figurino”. In: Aguiar, Flávio (org.). Pensamento e militância. São Paulo, Fundação Perseu Abramo. 


\section{Resumo}

A sociologia clandestina de Antonio Candido

Este trabalho procura discutir as relaçôes entre crítica literária e ciências sociais em alguns dos principais ensaios de Antonio Candido. Por meio da análise de "Dialética da malandragem" (1970) e "De Cortiço a cortiço" (1993), pretende-se identificar e demonstrar a procedência e a inspiração de certos modelos sociológicos subjacentes a esses ensaios, buscando por essa via articulá-los, respectivamente, com preocupaçôes derivadas da produção sociológica do próprio autor e com certos núcleos temáticos desenvolvidos pela chamada Escola Paulista de Sociologia. Na parte final, sugiro a possibilidade de apreender parte substantiva da produção crítica de Antonio Candido a partir de um diálogo estreito e criativo com questôes relacionadas com o temário do pensamento social brasileiro, remetendo a uma dupla inserção de tradições disciplinares, responsáveis pela composição de um projeto autoral cujas principais coordenadas articulam ensaísmo social e crítica literária, ciências sociais e análise estética.

Palavras-chave: Antonio Candido; História intelectual; Crítica literária; Escola Paulista de Sociologia.

\section{Abstract}

The clandestine sociology of Antonio Candido

This text discusses the relationships between literary criticism and the social sciences informing some of Antonio Candido's best known essays. Based on an analysis of 'Dialectic of malandroism' (1970) and 'From slum to slum' (1993), the article identifies and discusses the influence of particular sociological models on these essays, linking these models to concerns found in the author's own sociological work and to various themes developed by the São Paulo School of Sociology. In the final part, I suggest that much of Antonio Candido's critical output can be understood as an intimate and creative dialogue with questions related to central themes of Brazilian social thought, founded on his involvement in two distinct disciplinary traditions - an authorial project whose scope combined social essayism and literary criticism, social sciences and aesthetic analysis.

Keywords: Antonio Candido; Intellectual history; Literary criticism; São Paulo School of Sociology.
Texto recebido em 29/ 10/2007 e aprovado em $11 / 1 / 2008$.

Rodrigo Martins Ramassote é mestre em Antropologia Social pelo Departamento de Antropologia Social do Instituto de Filosofia e Ciências Humanas (IFCH) da Unicamp. Atualmente, exerce o cargo de antropólogo na III Superintendência Regional do Iphan, localizada no Maranhão. E-mail: ramasso te@hotmail.com. 